\title{
MARGARIDA VALE DE GATO: APRESENTAÇÃO DE MULHER AO MAR E ENTREVISTA
}

\author{
MARGARIDA VALE DE GATO: \\ PRESENTATION OF 'WOMAN TO THE SEA' \\ AND INTERVIEW
}

Tatiana Pequeno ${ }^{1}$

\section{RESUMO}

O presente texto objetiva introduzir o leitor na poesia da escritora portuguesa Margarida Vale de Gato a partir de questões relacionadas às temáticas feministas, de gênero e sexualidade considerando, para tanto, seu projeto poético intitulado Mulher ao mar, publicado pela primeira vez em 2010. Contém ainda uma breve entrevista feita com a poeta no final de 2017.

PALAVRAS-CHAVE: Margarida Vale de Gato; poesia portuguesa; crítica feminista

\section{ABSTRACT}

This text aims to introduce the reader to the poetry of the Portuguese writer Margarida Vale de Gato based on issues related to feminist, gender and sexuality themes, considering, for this purpose, her poetic project entitled Mulher ao mar, first published in 2010. It contains a brief interview with the poet in late 2017.

KEYWORDS: Margarida Vale de Gato; portuguese poetry; feminist criticism. 
(...)

Não dá para escrever de novo o cânone

nem há evolução contemporânea

no que é de género, no que há de impróprio

em amar com o corpo todo nela,

ânfora inebriada que se inclina

ao ritmo galopante do artista

que do fogo a invocou - na Índia -

ou - na Bíblia - fez com uma costela.

Não mais dest'arte o jugo ilusionista.

Margarida Vale de Gato, Mulher ao mar e Grinalda.

Neste ano de 2020 em que o livro Mulher ao mar, da professora, tradutora, e escritora Margarida Vale de Gato, completa uma década, oferecemos uma apresentação de sua poesia que, pela nossa visada, estabelece conexões com temas caros ao universo da crítica feminista, especialmente naquilo que diz respeito aos modos de construção e elaboração de uma dicção poética que enfrente "problemas de gênero" ou que trate de uma experiência que assuma os lugares da diferença sexual e discursiva que homens e mulheres ocupam em relação à linguagem e aos modos de expressá-la. Conforme a pequena entrevista realizada com a autora no final de 2017 - que ora apresentamos -, Gato compreende este projeto como imersão, isto é, como mergulho no mar da tradição. O pequeno conjunto de perguntas procurou provocar em Gato uma verticalização sobre questões que apareciam em seus livros de poesia até então publicados, Mulher ao mar (Mariposa Azual: 2010, 2013) e Lançamento (Douda Correria: 2016), especialmente naquilo que mais reverbera(va) como a relação com a tradição, com o feminino, com sua (in)comunidade. Passados quase três anos do inquérito proposto, pode-se verificar que a poesia de Margarida atualiza-se a partir daquilo que não cessa de se repetir. Mulher ao mar transformou-se em Mulher ao mar e Grinalda em 2018, uma terceira edição, acrescentada de diversos poemas, principalmente por um conjunto de 15 sonetos, cujo mote parece ser não o da coroa ou o do arranjo que sela a cabeça (o cérebro, por metonímia) feminina em cerimônias de casamento, mas o de uma outra coroação, a de instituição - pela repetição - de um modo de fugir às regras mortíferas da anulação subjetiva a que heteronormatividade costuma convencer e submeter as mulheres. Como aparece no nono soneto, "com regras que de cor sei, corrompo/ e busco língua nova que destape/ a tumba hetero-sapiens do discurso" (GATO, 2018, p. 17), este projeto poético procura esmiuçar com vigor a parte mortífera e trágica daquilo que há de impossível - psicanaliticamente falando - entre os homens e as mulheres. Esta poesia expõe, assim, algo de inassimilável na experiência do feminino, como se esta imersão no mar trouxesse revelações que expusessem também algo de trágico na/ da condição humana. 
Margarida Vale de Gato começou a relação com a tradição trágico-marítima num livro intitulado Mulher ao mar, a partir de 2010. Neste contexto, evidenciou não apenas uma nova perspectiva histórica diante do que funda, em certo sentido, a tradição literária portuguesa e sua relação com o mar, como procurou estabelecer um reposicionamento, um outro protagonismo, desta vez do feminino. E ao alocar a mulher como sujeito de uma produção poética que evoca e dialoga com a tradição (literária, da condição feminina, etc), Gato possibilita que se discuta o lugar e a pertinência dos Estudos Feministas, de Gênero e Sexualidade na própria história da literatura portuguesa pois sua poesia evidencia os entraves de uma existência sob a condição secundária e sempre do outro - e aqui cabe mencionar o legado de Simone de Beauvoir, que desenvolve longa reflexão sobre esta questão em O Segundo Sexo - da mulher ao dizer, no poema "Mayday": "não tinha a palavra de salvar,/ a senha que consagra e exonera;/ só tinha este corpo para entrar/ e um tacto insolente para abrir." (GATO, 2010, p. 16).

A mulher e o feminino desempenham, portanto, papel preponderante na referida obra de Margarida Vale de Gato: é através dele que se torna possível reestruturar a história da mulher com a tradição ocidental. $\mathrm{O}$ poema "Glosa da Nau Catrineta" é um exemplo de como este sujeito poético reelabora a aparição das três moças (uma referência também às três mitológicas parcas) oferecidas para casamento no folclórico poema atualizado e reelaborado por Almeida Garrett, no séc. XIX. Em Mulher ao mar, a glosa desdobra a figuração das três donzelas, colocando-as como sujeitos da ação do destino masculino ao mostrá-las como costureiras da vela do navio e da bainha que guarda as espadas, por exemplo. No poema popular recuperado por Garrett e sua tradição que põe em cena a pequena narrativa de um pai que oferece as três filhas ao Diabo, destaca-se a donzela mais bela que está chorando, permitindo a leitura de que ao feminino são esperadas apenas duas qualidades: a da beleza, para ornar e a do sofrimento, para purgar. $\mathrm{O}$ que Margarida Vale de Gato sugere, entretanto, é a protagonização por outras vias, permitindo, inclusive, um novo ethos para a mulher:

\author{
(...) Somos as irmãs que vêem \\ com um só olho de auguro \\ que as nossas agulhas têm \\ o passado e o futuro, \\ os mundos que há para além \\ e os mundos que há sob o mundo \\ onde os mortos vão penar: \\ e nosso pai, lá no fundo, \\ que quis o demo comprar \\ está no meio a chorar.
}

(GATO, 2010, p. 7)

O que parece estar em jogo no desafio inerente ao gênero da poesia "mote - glosa" é a função do pai, questão fundamental para as teorias feministas. O pai é a figura estruturante do sistema patriarcal que orienta 
a cultura ocidental. O patriarcado - e aqui cabe mencionar que alguns estudiosos contemporâneos preferem o uso da expressão cunhada por Pierre Bourdieu (2014): sistema social e cultural de dominação masculina - é que determina os usos da linguagem e dos discursos ordenadores da história, o que garantiria ao pai da "Nau Catarineta" o direito de oferecer as filhas ao Diabo para bodas com o objetivo de lucrar. No texto contemporâneo, nossa autora subverte, ainda que sob a tradição poética da redondilha maior, a tirania paterna, realocando as irmãs como sujeitos conscientes de que "as nossas agulhas têm/ o passado e o futuro,/ os mundos que há para além/ e os mundos que há sob o mundo" (Op. Cit)

Se, portanto, as parcas se reabilitam com seus próprios destinos e são capazes de tecer outros fios para as suas vidas, seria necessário, em Mulher ao mar, ir ao encontro da construção de uma voz e de um discurso próprios ao feminino, o que para a poeta significa emprestar a sua lírica para deixar falarem as raras (contudo, todavia) personagens do (de um certo tipo) cânone literário: Emily Dickinson, Virginia Woolf, Sylvia Plath, Christina Rossetti, dentre outras. Outrossim, o encontro da voz feminina consigo mesma teria a ver com uma conquista obtida por um trabalho íntimo de construção e assunção da voz da mulher. Trabalho íntimo e sobretudo custoso. Leiamos o poema que intitula o livro:

\author{
Mulher ao Mar \\ MAYDAY lanço, porque a guerra dura \\ e está vazio o vaso em que parti \\ e cede ao fundo onde a vaga fura, \\ suga a fissura, uma falta - não \\ um tarro de cortiça que vogasse; \\ especifico: é terracota e fractura, \\ e eu sou esparsa, e a liquidez maciça. \\ Tarde, sei, será, se vier socorro: \\ se transluz pouco ao escuro este sinal, \\ e a água não prevê qualquer escritura \\ se jazo aqui: rasura apenas, branda \\ a costura, fará a onda em ponto \\ lento um manto sobre o afogamento.
}

(GATO, 2010, p. 8)

O poema coloca em discussão a dimensão metafórica da mulher e seus desastres através da metáfora do afogamento, evocando esta imagem e a da deriva que, neste caso, serviriam de referências ao modo com que as subjetividades femininas flutuam nas culturas: "e eu sou esparsa, e a liquidez maciça”. É nesta direção também que Joel Birman, em Cartografias do feminino, parece encaminhar a reflexão basilar sobre as matrizes socioculturais de nossa civilização:

Enquanto pelo falo o sujeito busca a totalização, a universalidade e o domínio das coisas e dos outros, pela feminilidade o que está em pauta é uma postura voltada para o particular, 
o relativo e o não-controle sobre as coisas. Por isso mesmo, a feminilidade implica a singularidade do sujeito e as suas escolhas específicas, bem distantes da homogeneidade abrangente da postura fálica. A feminilidade é o correlato de uma postura heterogênea que marca a diferença de um sujeito em relação a qualquer outro.

(BIRMAN, 1999, p. 18, grifos nossos)

Com efeito, é ainda sob o efeito dessa água excessiva causadora de tanto afogamento que a "Mulher ao mar" operará o seu projeto literário (que a água e sua imagem territorializada da tradição) como "rasura apenas" que "branda/ a costura". O léxico da poeta e ainda o uso de um campo semântico capaz de colocar a morfologia a serviço da ambiguidade também movimentam o poema no seu ritmo ondulatório. Sinal inicial, o pedido de socorro do sujeito poético parece buscar uma possível salvação entre um afogamento e outro, enquanto resiste às vagas no seu modesto "tarro de cortiça”. Estaria a voz poética tentando surfar (sustentar-se, manter-se de pé) mesmo na atividade sinuosa de tamanho mar em movimento?

É relevante também observar que, a despeito do que propõe Judith Butler (2002) na epígrafe que selecionamos, a crítica feminista tem o objetivo de questionar o gosto pela abjeção ao feminino e a relação de inaceitabilidade pelos códigos inteligíveis de nossa cultura de uma produção poética que vise à construção de um sistema que não seja unilateralmente androcêntrico. Assim, enquanto a tradição está aliada a uma lógica canônica, isto é, eleita por um especificado grupo capaz de influenciar e determinar direcionamentos e sentidos que visem a uma seleção estética, por exemplo, a crítica feminista demanda não apenas um revisionismo cultural mas sobretudo a formação de uma voz habilitada a tratar de uma experiência de vazio ( da falta e do "vaso em que parti" do poema anterior ) a que as mulheres foram destinadas na maioria dos tempos.

O soneto "Émulos", de Mulher ao mar, também nos encaminha para uma discussão em que a ideia de diferença precisará ser discutida. Vejamos:

Foi como amor aquilo que fizemos ou tacto tácito? - os dois carentes e sem manhã sujeitos ao presente; foi logro aceite quando nos fodemos

Foi circo ou cerco, gesto ou estilo $\mathrm{o}$ acto de abraçarmos? foi candura o termos juntos sexo com ternura num clima de aparato e de sigilo.

Se virmos bem ninguém foi iludido de que era a coisa em si - só o placebo com algum excesso que acelera a líbido.

E eu, palavrosa, injusta desconcebo o zelo de que nada fosse dito e quanto quis tocar em estado líquido.

(GATO, 2010, p. 23) 
O referido texto parece querer, por meio de um formato tradicional de poesia, o soneto, introduzir uma discussão a respeito da disputa entre as representações do homem e da mulher ("os dois carentes”) na prática dos envolvimentos afetivos e da sexualidade. Onde a tradição permitiria a congruência, o encaixe e o poema como ilustração da imagem cliché da chave-fechadura, entretanto, não acontece. Surge, do encontro, um confronto admitido pelo título do poema: émulos como adversários, concorrentes, rivais. Ou seja, vai se configurando, a partir deste jogo de forte carga sexual, a incongruência entre os amantes: de um lado, a voz poética "palavrosa" desejosa de acessar o "estado líquido" e do outro uma referência silenciosa, que parece nada demandar além do "zelo de que nada fosse dito".

É neste contexto que passa a ser fundamental discutir os posicionamentos que a tradição impôs às dimensões do feminino. Porque no poema acima lido, a voz poética feminina "palavrosa” rompe com a condição silente aferida à mulher e permite o seu trânsito num território reivindicatório que alude à luta ancestral das mulheres ao direito de exposição enquanto seres de linguagem e do desejo, o que de antemão expõe a nervura de um conjunto de tensões e embates ontológicos (para retomar uma preocupação filosófica de Judith Butler) visíveis na escrita produzida por mulheres. Não obstante,

(...) a solidão da artista feminina, seus sentimentos de alienação em relação aos predecessores masculinos junto com sua necessidade de precursora e sucessora fraterna, sua percepção premente da necessidade de um público feminino junto com seu medo do antagonismo dos leitores masculinos, sua timidez culturalmente condicionada em relação à autodramatização, seu temor da autoridade patriarcal da arte, sua ansiedade e relação à impropriedade da invenção feminina - todos esses fenômenos da "inferiorização" marcam a luta da mulher escritora por autodefinição artística e diferencia seus esforços de autocriação daqueles de seus pares masculinos.

(KAPLAN apud SHOWALTER, 1994, p. 41, com grifos nossos)

É persistindo no processo criativo que a mulher poderá ir ao encontro não daquilo que a completaria (um homem, a imagem fetichizada da chave na fechadura), de modo que a escrita contemporânea e seus estatutos críticos-políticos evocam uma reflexão sobre a consciência da implicação de um eu-feminino e não um adendo de outro ser, como a tradicional metáfora bíblica sugere sobre o surgimento e o espaço destinado à existência da mulher, também visível no poema "Ressabiadas":

\section{(...)}

Costumes que frequentamos:

o arame da loiça, os panos dos pratos, os ganchos e as linhas do estendal, a vinha-de-alhos, o fogão,

o alguidar, guardamos os restos, torcemos

os trapos, os nossos recados, os nossos sacos,

os nossos ovos. 
Certamente que eles, em grande maioria,

escanhoam os queixos e gostam

de arejar, mas são médicos, polícias,

engraxadores, economistas

e os vários naipes da banda filarmónica

nós somos todas domésticas (...)

(GATO, 2010, p. 45)

Por mais que os ativismos feministas (tradicionais, de mulheres negras, de mulheres latinas ou periféricas) venham sendo tolerados e admitidos, sobretudo em espaços virtuais e as mulheres estejam conseguindo ocupar - cada vez mais desafiadoramente - lugares antes impensáveis para a condição feminina, nunca a violência se mostrou tão operante. De modo semelhante, a violência simbólica que restringe a mulher aos espaços domésticos, já analisada por exemplo por Virgínia Woolf (em Um teto todo seu e "Profissões para mulheres", etc.) em textos famosos, a violência ainda sistematiza boa parte da herança linguística recebida pelo feminino e tudo que se circunscreve no seu entorno (daí ser relevante verificar também o cruzamento dos transativismos com os movimentos de mulheres e entender os motivos que levam ao excessivo ódio às travestis e às pessoas-trans, sobretudo àquelas que abdicam de uma performance masculina tradicional de gênero). Dito de outro modo: variadas formas de violência ainda persistem em situações variadas, circundando as mulheres, conforme se verifica no poema escrito por uma mulher acadêmica, Margarida Vale de Gato, nossa autora. Consequentemente, enquanto os homens escolhem seus destinos e os lugares sociais que ocuparão no mundo de acordo com a constituição de suas subjetividades ("e os vários naipes das bandas filarmônicas", como demonstram diversos dos seus poemas), às mulheres ainda devem se contentar com qualquer atividade ou voz limitada à lógica de "nós somos todas domésticas". De modo que à literatura (e à poesia, evidentemente) também cabe - como bem mostraram as Novas Cartas Portuguesas, obra certamente influenciadora da poética de Gato, como demonstra nossa entrevista -, a denúncia, o questionamento, o confronto, o gesto vigoroso da reivindicação da linguagem.

Se a poesia insiste, portanto, e é marca indelével de determinadas visadas culturais, parece importante que a literatura portuguesa esteja em contato com as demandas de nosso tempo. Deste modo, entende-se que o contemporâneo deve reconhecer a voz das antigas musas no que diz respeito à feitura do literário, mas deve lembrar também que a própria poesia, se não recolhida com o devido apreço entre aqueles que estimam a arte no seu tempo, pode dar sinais do seu cansaço. E foi neste sentido que Camões pontuou a necessidade de a arte de seu tempo também ser lida e estimada quando, ao final do último canto de Os Lusíadas, declara: No mais, Musa, no mais, que a Lira tenho/ Destemperada e a voz enrouquecida,/ E não do canto, mas de ver que venho/ Cantar a gente surda e endurecida (Lus, X, 145). Com efeito, estimar a arte contemporânea significa, dentre outras coisas, lê-la profissionalmente, isto é, compreender que o universo acadêmico também deve estar atento e ser observador crítico do que é produzido na sua contemporaneidade. 
E para finalizar, julgamos conveniente observar o que sugere a eminente ensaísta portuguesa Isabel Pires de Lima em seu famoso Vozes e olhares no feminino, de 2001:

Não foi, porém, como ficou dito, a conviç̧ão de que exista uma "escrita feminina" que esteve na base desta iniciativa, mas a certeza de que a escrita de autoria feminina, a voz feminina, ainda é ouvida como voz segunda, como dialecto, e que precisa portanto de criar espaços e momentos para ser ouvida, mais ouvida. Ouvida na capacidade de universalidade e de abrangência que ela tem, independentemente de todas as marcas de gênero que eventualmente possa ter.

(LIMA, 2001, p. 14)

E é neste sentido que entendemos que a literatura portuguesa permanece viva e demandante de reflexões igualmente caras ao nosso tempo. Oxalá possamos permanecer dialogando com os impasses e tensões desta época sinistra para, nas tentativas de ouvi-la, poder transformá-la artística e revolucionariamente, para que possamos também permear de esperança naquilo que poderia ser o presente:

Que faço só poema onde haja dentro carne e corpos prefiro que cubram como casas Melhor ainda tendas, asilos fugazes um ou dois furos, ventos, humidade, dádivas (GATO, 2010, p. 67)

\section{ENTREVISTA COM MARGARIDA VALE DE GATO}

1) Entrevistadora: Margarida, obrigada pela generosidade em nos conceder tal entrevista. Certamente ela abrirá caminhos variados para os seus leitores brasileiros. Gostaria de começar evocando seu primeiro livro, Mulher ao Mar. Passados alguns anos, como você entende a sua contribuição para uma discussão que a mim parece delicada na literatura portuguesa - a da relação da lírica com os problemas de gênero - ainda que tenhamos Florbela Espanca, Luiza Neto Jorge e Maria Teresa Horta, por exemplo, como nomes mais ou menos organizadores de uma dicção poética no feminino? Como você vê, hoje, seu livro de estreia? Ele dialoga com a tradição - é claro - mas parece irromper numa autenticidade muito diferente desta clave "portuguesa", o que teria a ver com seu lugar de professora de língua não-vernácula e de tradutora, suponho. Você concorda com tal suposição?

Margarida Vale de Gato: Mulher ao Mar é o meu primeiro livro, mas foi um livro que eu sempre pensei não se esgotar na sua estreia, pois para mim tocava uma questão que eu não podia resolver mas que continuaria a inquietar-me: a da liberdade, primeiro, e a da liberdade feminina, segundo. A liberdade, primeiro, posta em poesia, passa por uma construção em introspeção, onde, como creio que disse Ruben Darío, a língua é 
ginete do pensamento e não o seu cavalo. Mulher ao Mar é uma espécie de diário público, não cronológico mas de alguma forma progressivo, de uma persona que eu vou construindo e que às vezes até permito ser o meu próprio ginete - por isso é um livro que eu quero que permaneça comigo pelo menos por algum tempo, enquanto vou expandido e redefinindo a geografia desta persona. Admito também que a minha fé na língua como esporeadora do pensamento seja excessiva, pois que há tantas linguagens, e eu escoro-me na fundamentalmente verbal. No entanto, ao fazê-lo, não posso deixar de colocar a minha língua em confronto - ou, quando mais meiga, diálogo - com a tradicional dominação masculina. Daí o ponto segundo, da liberdade feminina. No desafio da lógica patriarcal, vertical, comparativa-abusiva e limitadamente representativa do outro, é preciso rebeldia e iconoclastia. Eu penso que ela tem existido na poesia portuguesa, sim, sobretudo desde Natália Correia (porquê ainda continuar a querer esquecer Mátria e a Madona, de 1968 e 1969?), de Minha Senhora de Mim de Maria Teresa Horta e das Novas Cartas Portuguesas, no início dos anos 70. Mas a lista continua, estendendo-se a Maria Judite de Carvalho, Luiza Neto Jorge e até, mesmo que nem sempre seja evidente, a Sophia de Mello Breyner. Na literatura brasileira, recordo Hilda Hilst e Adélia Prado, esta última com uma atenção à componente espiritual da sexualidade desbragada, de vários géneros e seres, que eu acho muito refrescante. Não que a escrita tenha necessariamene sexo; tem, porém, inflexões de género, que não raro precisam de alternativas, e estas podem ser escritas também por homens (é o caso de Al Berto, em Portugal), uma tentativa de ir contra a tradição de dominação masculina e de explorar estruturas de sensibilidade reveladoras de tensões internas e afetivas, processo que muito deve aos auspícios do modernismo anglo-americano, com escritoras fortes de ambos os lados do Atlântico, como Virginia Woolf ou Gertrude Stein e H. D. Recorro muito a este padrão anglófono, sim, que tem depois o boom da exposição feminina na poesia dita "confessional" (mas na verdade altamente mítico-surreal) de Sylvia Plath ou Anne Sexton. Talvez estas mulheres me tenham ensinado algo da dicção, de persistente e enfadada paciência (caso Adrienne Rich), que descola de uma certa nostalgia auto-vitimizadora. Quanto ao labor de tradução em conjunto com o trabalho da poesia, creio que é um processo conjugado para perceber melhor como ser outro(a) e nos valermos na heterogeneidade e diversidade.

2) Entrevistadora: Como pesquisadora da área dos estudos de gênero e sexualidade no contexto das literaturas de língua portuguesa, verifico uma forte ressonância das Novas Cartas Portuguesas em seu primeiro livro. Você poderia nos dizer qual é a relevância das Novas Cartas Portuguesas para a sua primeira obra? Acredita que as Novas Cartas Portuguesas são um livro excessivamente político ou engajado ou que representa, em Portugal, a demanda de uma geração já (muito) (ultra)passada? 
Margarida Vale de Gato: Não sei avaliar a dimensão de Novas Cartas Portuguesas em Mulher ao Mar embora saiba dizer que foi nesta última obra que encontrei a expressão mais veemente de como trabalhar a partir de/ e contra certos tropos românticos lusitanos, como seja o "descabelismo" sentimental feminino. O meu poema "Prendas" (Cabalmente instruídas mas / pouco experimentadas / somos as cabras-/-cegas da literatura" é herdeiro directo de Novas Cartas. Trata-se de um livro que foi uma pedrada no charco não só em tempos de repressão ideológica nacional, mas ao nível do que de mais experimental e altruísta pelo mundo se fazia (o pacto de não-autoria das três feministas solidárias é, só por si, uma abdicação da propriedade associada ao patriarcado). A desconstrução das formas, o jogo com a tradução e até com a transição de línguas e discursos, para além do revisionismo histórico que implica pleitar com a freira co-dependente, é uma construção toda ela projetada para uma utopia ainda hoje à frente do seu tempo

3) Entrevistadora: É possível pensar em Margarida Vale de Gato como poeta sem as influências diretas ou indiretas das literaturas de língua inglesa ou sem a verve tradutora de um Henri Michaux, por exemplo?

Margarida Vale de Gato: $\mathrm{O}$ encontro com a tradução foi a experiência mais libertadora da minha carreira... ou mesmo da vida, considerando que aconteceu aos treze anos, quando vivia nos Estados Unidos e estava a tentar melhorar o meu francês traduzindo Jacques Brel. Conseguir chegar a expressões funcionalmente equivalentes, mas com importantes modulações formais e implicações semânticas culturais, maravilhou-me - como ainda hoje - pela dimensão de sentidos que encontramos nos modos de estruturação de diferentes línguas e linguagens. Além de proporcionar espetaculares mudanças de perspectiva. E essa mudança de perspectiva fornece uma predisposição para a leitura profunda, modalizada e polissémica — modo em que tenho tido o privilégio de ler grandes autores, como Henri Michaux, precisamente.

4) Entrevistadora: Seu livro de poesia, Lançamento (Douda Correria, 2016), parece transmitir a ideia de que a poesia, embora não seja propriamente salvífica, funcione como uma espécie de fronteira que, como muito bem dito no último texto do referido volume, preserva alguma negatividade necessária para nos constituir na respeitabilidade mútua. É possível escrever sem melancolia? Lançamento pode ser lido como - lembro agora de uma canção de uma banda canadense de post-rock, A Silver Mt. Zion, cujo título é “The triumph of our tired eyes”) um passo à frente na tarefa de permitir também o negativo da/ que é a melancolia (penso no poema "Nuno" e seu primeiro verso, "nós e a nossa imensa angst")?

Margarida Vale de Gato: Por acaso penso que a melancolia e $a$ angst são sentimentos algo diferentes. A melancolia é uma coisa romântica, motivadora de odes outonais, um tanto acabrunhada com o passado e intimidada com os mestres. Curioso teres invocado o pós-rock, porque para 
mim a angst é uma coisa mais punk, com algo de destrutivo, mas com um pé apontado para a revolução e para a liberdade. Talvez seja esse o impulso de Lançamento, e nele há um poema em particular, "Luís”, em que contraponho à ideia dos tempos tardios de uma poesia melancólica - muito em voga nos estudos literários desde Harold Bloom - o olhar que se volta para a madrugada e o nascimento do sol, ainda que provavelmente seja um olhar insone, de toda uma noite boémia: "E que a poesia, se tem de recordar / será do amor que não se redime / nunca da gana absurda de o fazer. // E de um incrível viço de erva / que sim, que frágil - que nítida - ferve / nos nossos olhos ao alvorecer." Há aqui também uma vénia e uma rasteira ao "Sentimento de um Ocidental" de Cesário Verde. Deve ser a pequena punk dentro de mim.

5) Entrevistadora: Lançamento sugeriria, a meu ver, a constituição de uma rede ou de uma comunidade mínima para "atravessar" o "deserto do mundo", para usar uma imagem de Sophia de Mello Breyner Andresen. A Margarida vê em sua própria poesia alguma marca do que seja um testemunho de resistência diante da referida imagem de desertificação ou embrutecimento da linguagem?

Margarida Vale de Gato: Creio que na pergunta anterior já fui suficientemente ambiciosa em relação à minha poesia. Mas na tua pergunta há duas coisas diferentes, parece-me: a Sophia a falar do deserto do mundo, e tu talvez a sugerires o embrutecimento da linguagem. Um poeta acredita e desconfia da linguagem, creio. E apesar da elevada taxa de suicídio entre poetas eu creio, com William Carlos Williams, que também há quem morra pela falta de poesia, embora isso não venho nas notícias.

Vale de Gato?

6) Entrevistadora: $O$ que é a beleza ou o sublime para Margarida

Margarida Vale de Gato: Penso que os meus dois títulos até agora apontam para o duplo movimento do que é o sublime para mim: imersão e ascenção. Ainda não cheguei à segunda parte da equação.

\section{REFERÊNCIAS BIBLIOGRÁFICAS}

BEAUVOIR, Simone. O segundo sexo. Nova Fronteira: Rio de Janeiro, 2009.

BIRMAN, Joel. Cartografias do feminino. Editora 34: São Paulo, 1999.

BOURDIEU, Pierre. A dominação masculina: a condição feminina e a violência simbólica. Rio de Janeiro: BestBolso, 2014.

BRITO, Bernardo Gomes de. História Trágico-Marítima. Rio de Janeiro: Lacerda Editores / Contraponto, 1998.

BUTLER, Judith. "Como os corpos se tornam matéria: entrevista com Judith Butler”. Revista de Estudos Feministas. vol.10 no.1 Florianópolis/ 
Jan. 2002. Disponível em: http://www.scielo.br/scielo.php?pid=S0104-026X2002000100009\&script=sci_arttext. Acessado em 20 de maio de 2018.

. Cuerpos que importan - Sobre los limites materiales y discursivos del "sexo". Buenos Aires: Paidós, 2002 b.

. Problemas de gênero - Feminismo e Subversão da Identidade. Civilização Brasileira: Rio de Janeiro, 2012.

CAMÕES, Luís Vaz de. Os Lusíadas. Porto: Porto Editora, 1980.

FERRÉ, Pere. A Nau Catrineta. Viseu: Quetzal Editores, 1983.

GARRETT, Almeida. Romanceiro. Edição revista e prefaciada por Fernando Castro Pires de Lima, vol. I, II e III. Porto: FNAT, 1963.

GATO, Margarida Vale de. Lançamento. Lisboa: Douda Correria, 2016.

_. Mulher ao mar. Lisboa: Mariposa Azual, 2010.

_. Mulher ao mar. Lisboa: Mariposa Azual, 2013.

. Mulher ao mar e Grinalda. Lisboa: Mariposa Azual, 2018.

GUATTARI, Félix \& ROLNIK, Suely. Micropolítica: Cartografias del Deseo. Madrid: Traficantes de Sueños, 2006.

LIMA, Fernando Castro Pires de. A Nau Catarineta - ensaio de interpretação histórica. Lisboa: Portucalense Editora, 1954a.

LIMA, Francisco Ferreira de. O Outro Livro das Maravilhas. Rio de Janeiro: Relume Dumará, 1998b.

LIMA, Isabel Pires de. Vozes e Olhares no Feminino. Porto: Porto Editora, 2001c. LLANSOL, Maria Gabriela. Um falcão no punho. Lisboa: Relógio d'água, 1998.

PEQUENO, Tatiana. "Novas Cartas e depois: contra a periferia do feminino." In: Revista Mulheres e Literatura. Vol. 14, 2015. Disponível em: http:// litcult.net/novas-cartas-e-depoisainda-contra-a-periferia-do-feminino-2/. Acesso em 08 de março de 2016.

PERES, Damião. História dos Descobrimentos Portugueses. Porto: Vertente, 1983.

PIGAFETTA, Antonio. A Primeira Viagem ao Redor do Mundo - O diário da expedição de Fernão de Magalhães. Porto Alegre: L\&PM, 1985.

SEIXO, Maria Alzira \& CARVALHO, Alberto (orgs.). A história trágico-marítima: análises e perspectivas. Lisboa: Cosmos, 1996.

SEIXO, Maria Alzira. Poéticas da Viagem na Literatura. Lisboa: Edição Cosmos, 1998. 
SHOWALTER, Elaine. "A Crítica Feminista no território selvagem”. In: Tendências e Impasses - O feminismo como crítica da cultura. Rio de Janeiro: Rocco, 1994.

SPIVAK, Gayatri Chakravorty. Pode o subalterno falar?. Belo Horizonte: ED.UFMG, 2010.

WILLMER, Rhea S. Nau Catarineta: da jornada marítima à literatura infanto-juvenil. Rio de Janeiro: Faculdade de Letras da UFRJ, 2009. Dissertação de mestrado do Programa de Pós-graduação em Letras Vernáculas da UFRJ.

WOOLF, Virginia. Profissões para mulheres e outros artigos feministas. Porto Alegre: L\&PM, 2012

Recebido para avaliação em 31/01/20 Aprovado para publicação em 08/02/20

\section{NOTA}

1 Professora de Literatura Portuguesa do Instituto de Letras da Universidade Federal Fluminense. Coordenadora do Grupo de Pesquisas Corpo, gênero e sexualidades nas literaturas de língua portuguesa e membro do Grupo Internacional de Pesquisas Intersexualidades, coordenado pela Profa. Ana Luísa Amaral, da Universidade do Porto, em Portugal. 